\title{
A MODEL OF INTEGRATED COMMUNITY DEVELOPMENT
}

\author{
Ana NIȚU ${ }^{1}$ \\ Costin $\mathrm{CACE}^{2}$
}

DOI: 10.35782/JCPP.2020.3.04

\begin{abstract}
The study aims to present and analyse a model of good practices in community development, based on an integrated approach and bring a better understanding of the advantages of such an approach. The study is based on a project implemented in 12 communities, throughout 46 months, which aimed to improve access to educational and health services as well as build strong communities and inter-ethnic relations. Following the implementation of the project, an evaluating research has been carried out in order to determine the changes and development the project has achieved. The current case study focuses its analyses on data gathered from the particular research, namely on 2 communities and the actions implemented as well as the results they produced. Therefore, analyzing the outcome of the intervention, augmenting the need and benefits of the integrated approach in development projects.
\end{abstract}

Keywords: Community development, Integrated development, Roma communities, Local empowerment, Local Initiative Groups

\section{Introduction}

\subsection{Project description}

"zefiR. Together for Empowerment" was the initiative of a consortium coordinated by Terre des hommes and formed of Amare Rromentza, Impreună Agency, PACT Foundation and Pestalozzi Foundation. Habitat for Humanity Romania and SASTIPEN have also joined us in the project as associated partners. Through this

${ }^{1}$ Faculty of Sociology and Social Work, University of Bucharest, Romania, Email: anna.nitu97@ gmail.com

${ }^{2}$ Faculty of Sociology and Social Work, University of Bucharest, Romania, Email: costincace@ gmail.com 
project, the consortium aimed to improve the access to education and healthcare for over 20.000 people in rural and small urban areas, from 12 communities, in three districts from South-West Romania: Olt, Dolj and Gorj. The population targeted in this project were persons that belong to vulnerable groups, mainly Roma, especially women, young people and children.

zefiR was based on an integrated approach regarding health and education as main areas of intervention, alongside housing - as a complementary field, based on community development as an underlying approach. Throughout the 46 months of the project, the beneficiaries and the other members of the 12 communities were involved directly in all stages of the implementation, from the participatory analysis of the community needs, to the impact assessment, with wide participation of all interested stakeholders.

The consortium aimed at building strong communities and links between Roma and other ethnic groups, focusing on three directions of action: improving access to quality educational and health services and increasing the capacity of the 12 communities for long term action.

\subsection{Project approach}

The project relied on a bottom-up approach. Activities were conceived and implemented by allowing beneficiaries to participate in all the steps and components of the project, so that the interventions were constructed based on specific and documented needs. Community members were empowered to participate in the decision-making process at different levels in project implementation. In this sense, the project activities were pursued to build trustworthy relationships among community members and ensure a local ownership over the project. Also, the activities in the project were anchored on an integrated approach. The project included multiple areas of interventions and proposed various solutions to the challenges faced by vulnerable groups, thus creating synergies among ongoing operations and activities. Since social inclusion issues is very complex and challenging, the project undertook a long-term perspective in which change was understood as a gradual process of cultural learning and capacity building.

\section{Literature review}

Community development, ever since its inception consisted of economic and political development objectives. "It held forth the promise of both building grassroots democratic institutions and contributing to the material well-being of rural people" (Ruttan, 1984). The process of community development has been seen as directly involving the people in finding a solution to their problems, as well as employing a democratic process in solutioning the problems. It has also focused on the transfer or information, know-how, skills and knowledge to people of a community in order for them to be able to resolve their problems. The process of community development was, 
as seen by Ruttan "rooted in the concept of the worth of the individual as a responsible, participating member of society...It was designed to encourage self-help efforts to raise standards of living and to create stable, self-reliant communities with an assured sense of social and political responsibility" (Ruttan, 1984).

Community development and its integrated approach has been discussed by Jones and Wiggle 1987, mentioning the fact that for integrated rural development to occur, a new approach of the management and resources needs to be found. They mention that this new type of integrated development needs to "be established away from the social welfare connotations of the past, and towards realizing its true economic potential, which, in turn, has a number of political implications" (Jones \& Wiggle, 1987).

In the case of the Roma communities, community development, as mentioned by Ryder, Rostas \& Taba (2014) has often fallen into the "trap of promoting forms of therapy and tokenism" therefore the inequality problems, both institutional and structural ones remaining unresolved (Ryder, Rostas, \& Taba, 2014). Adressing the problem of Roma inequalities and Roma communities, Sandu (2005) mentions that the general idea involving Roma developemnt revolves around employment and income, which are believed to be the root of the inequalities and discrimination, by the standard Roma elites at the local level. Sandu mentions that Roma people have a very low employment and therefore very low income due to "their low education resources in the context of general low opportunities for unqualified work and, sometimes as a result of work hiring discrimination." He mentions however that poor housing and health are two factors that play a decisive role too, consequently, leading to more problems and underdevelopment of the communities (Sandu, 2005).

This is where community development projects that involve an integrated approach, focusing on not just employment or education come into play. Integrated approaches that revolve around a series of components and implementation of diverse activities in a wide range of directions, such as housing, health, skill-learning or civic involvement.

Integrated development projects as stated by Masset (2018) are often designed as "packages of multiple interventions" in various fields such as social protection and community-driven development projects. Although these packages are implemented in a specific area, for example nutrition or employment, they include "include many different interventions in the belief that they are all required to achieve the stated goal and that they reinforce each other." (Masset, 2018)

\section{Methodology}

The purpose of the evaluation was to identify the results and the impact of the implemented activities in the 2 communities from the South-West region (Oltenia) and analyse the results and impact of the activities in the project at the community level, carrying out a distinct analysis for each segment, education, health, housing and 
community development. The efficiency of the utilization of resources and the way in which the integrated approach functioned will be analysed.

\subsection{Methods and instruments}

The survey took place in twelve communities that have been chosen beforehand to be part of the "zefiR: Together for empowerment" project. The survey was conducted between November $12^{\text {th }} 2018$ and January 12 $12^{\text {th }} 2019$. The study consists of several quantitative instruments, along with qualitative ones - mixed methods.

The core quantitative instrument comprises 217 variables from all relevant fields, such as health, education, housing, public participation, interethnic relations, along with data regarding the household (income, regularity of income, sources of income, employment status), and demographic data for the selected respondents (gender, age, level of education, religion, ethnicity). The sample consists of 750 valid questionnaires, each community being assigned a certain number of minimum applied instruments. We have tried to maintain the same sampling structure from the baselines study and approximately the same number of in order to be able to produce a further comparison. Out of the 750, for the purpose of this analyses, we included the questionnaires applied in the 2 communities.

The study was carried out using a simple random sample of Roma and nearby nonRoma households. Most of our operators received help in applying the questionnaires from local individuals, both Roma and non-Roma, some of them being familiarized with the zefiR project and the aspects of carrying out research, others having little experience with data collection and the project itself. Each of our operators were trained into correctly applying the questionnaire and selecting the households. Our teams have been in each and every community to make sure everything was progressing as planned.

The household selection was completed using the random walk method, as following: Once the operators were on the first street of the Roma neighbourhood, they were asked to select from the left side the uneven numbered households $(1,3,5$, etc.), or from the right side of the road the even numbered households $(2,4,6$ etc.) then proceed onto the next parallel or perpendicular street in relation to the first street, and choose the other side of the road than they have previously chosen.

Besides the quantitative instruments the study also included qualitative instruments. The qualitative part of the study consisted of focus groups with aflateen members or their coordinator, focus groups with the local initiative groups members, along with interviews with local authorities' representatives and interviews with representatives of the main seven organizations that took part in the implementation of the zefiR project for a better understanding of the project as a whole. The obtained qualitative data has helped getting an insight on the way the projects was implemented, the problems 
certain actors were faced with along the way as well as the positive aspects of the beneficiaries and their experiences.

\section{Context}

\subsection{Communities description}

The village Ocolna is situated in the south - eastern part of Dolj County, bordering Olt County, at a distance of $65 \mathrm{~km}$ from Craiova and 19,6 km from Dăbuleni town, which is the nearest urban settlement. It consists of three villages: Amărăștii de Jos, Praporu and Ocolna. From the demographic viewpoint, Amărăștii de Jos has 5520 inhabitants, out of whom 1223 are Roma (census 2011). The Roma community is compact, located outside the village, but easily accessible due to the county road that connects it with the town of Dabuleni. Ocolna village, located $10 \mathrm{~km}$ from Amărăștii de Jos has a population that is $100 \%$ Roma. The Roma from the community speak both Romany and Romanian. In terms of religion, the majority are Orthodox and only few Protestants.

The village Barca is located in the southern part of Dolj County, on the left bank of Desnauti River, $40 \mathrm{~km}$ far from Craiova. It has a population of 3689 inhabitants out of which 754 are self-identified Roma (2011 Census) and 1047 hetero-identified (unofficial sources).

The Roma community has a compact-type living style in the Dragalina district, and a dispersed-type one on the streets Targului and Burebista, while the 20 Rudari (woodworkers) families are placed "towards the pond". The Roma from the community speak both Romany and Romanian. Regarding the cultural make-up of the Roma communities the following groups could be identified, respectively: woodworkers (Rudari, they identify themselves as Roma), lingurari wooden spoon makers (lingurari), brick makers (caramizari), and farriers (potcovari). Next to them live gadjo, [tismanari respectively representatives of inter-ethnic marriages between Roma and people of other ethnicities] (the oldest attested in the monograph, about 20-30 families), lautari fiddlers (lautari), and clothes tinkers (costorari, makers of traditional clothing in the village), nomad gypsies (laieti).

The Roma people declare themselves as Orthodox. There are no Roma people without identity documents.

\section{Components and results}

\subsection{Community development}

The activities conducted in the spheres of education, health and housing were supported through community development interventions that relied on participatory 
approaches. Community development initiatives were focused on the identification and prioritization of socio-economic needs at local level, as to increase the general participation of community members in developing and implementing sustainable initiatives. Local problems were approached by mobilizing local resources to address identified community needs.

The main objective of the community development component was to empower local communities through leadership development and capacity building. Activities were directed towards mobilising communities to exercise a greater control over their local contexts by fostering a sense of ownership of local policy decisions and programs. Another goal of the project was to improve the perception of Roma minority at local, regional and national levels, while cultivating self-confidence of community members in taking initiatives to improve their life conditions. Therefore, the project aimed to improve problem solving capabilities and enrich intercommunity dialogue.

The community development activities evolved around the formation and coagulation of local initiative groups. Local initiative groups are understood as forms of cooperation to stimulate social cohesion, civic participation, and community trust building. Each initiative group worked together with a community facilitator and realized an inventory of resources available in the community (e.g. human, material, financial and symbolic resources). These types of resources were correlated with the socio-economic needs experienced in the community, thus constituting the grounds on which local initiative plans were elaborated. However, local action plans are continuously adapted and enriched in relation with local conditions and social change. In order to ensure a high quality of strategies stipulated in local action plans, members of local initiative groups and representatives of local authorities participated in training sessions which improved their knowledge and skills in leadership, problem solving, social and financial management. As a result, community members were trained in the elaboration of action plans, project writing, public participation, advocacy and negotiation with local authorities, resource mobilisation, fundraising and communication, child protection etc.

In the two communities, the activities of community development have been accomplished according to the methodology, and produced similar results in terms of: community awareness, participation in the evaluation of community needs, setting the priority order for the interventions and actual involvement in all the actions initiated by the community. The local group of initiative GIL from Barca, although having a consistent structure, worked less intensely in the beginning, that that from Ocolna, because of the lower number of activities performed within this community. The increased mobilization of the community members appeared when, using the integrated approach, more social actors and more aspects of the social life were involved, when the interventions were done in multiple areas: education, health care, 
dwelling and economic development. In the case of the Ocolna community, one can notice important changes, both at the individual, and at the community level. The empowering effects of community participation in poverty reduction manifest at the individual and collective levels, at the individual level, giving people the knowledge, skills and confidence to address their own needs and advocate on their own behalf improves their capacity for collective. Participation in collective action gave individuals the resources to exercise agency through their voice, empowering people through capacity building increased the likelihood of their participation in community activities. Increased levels of empowerment allowed the community to have influence over things that matter and obtain power over decisions, enabling them to move from powerless non-participants to active and effective citizens.

\subsection{Education}

The main objective of the educational activities was to reduce educational disparities between disadvantaged groups and majority population by supporting constructive pedagogical approaches and by developing inclusive learning cultures.

The project aimed to reduce educational gaps through multiple and complementary interventions that covered a wide range of interlinking topics and approaches. Therefore, the educational objectives of the project were planned to be accomplished through different types of activities:

1. Activities designed to increase access to quality educational services: Access to quality education was improved by developing structures and institutions that support children's active participation in the educational process. So, 'afterschool programs' were initiated and kindergarten groups were set up and fully furbished;

2. Activities designed to develop an inclusive and supporting pedagogical culture: To ensure the efficiency of the educational services developed in the project, the staff working with children within the zefiR institutional structures were trained as to acquire knowledge and skills on various components: methodology of organising 'after school' programs, social implications of mentoring activities, principles of parental education, and techniques of intercultural education. Moreover, other relevant social actors such as teachers, educators, educational assistants and mentors participated in training courses aimed to increase their level of competence regarding an intercultural approach to equity and social justice

3. Activities designed to raise awareness on the importance of education: This component of the project worked towards producing some changes in the attitudes towards the role of education in personal development. It included mentoring programs designed to increase the level of participation in school activities among children and parents. Children were exposed to positive learning experiences in school context that might work on their level of engagement in formal education. Also, parental mentoring 
sessions were organised in order to increase the level and quality of parental participation in school decision structures and activities. Parents were guided in consolidating both a gratifying relationship with their children and a constructive collaboration with teachers and other school representatives.

4. Activities designed to support inclusion in education: Different instructional and informational resources were developed and disseminated in order to articulate an inclusive culture of teaching. These resources include: an intercultural / bilingual preschool curriculum, an intercultural education guide, and a guide for parental mentoring. Not only that these materials define the approaches and practices followed in the implementation of the project, but they also draw some directions that might be used to support inclusion in education on the long run.

The effects noticed in the two communities seem to be significantly different. The parents from Ocolna appreciated the higher involvement of their children in kindergarten and in school, and the better motivation for them to be included in educational programs. For the children from Bărca, the extra-school activities brought along a benefit for their spare time, and opening towards other localities through the trips organised during the project, therefore bringing social inclusion at the individual and educational level. The education component and the activities implemented have managed to address the importance of education, the social exclusion problem, along with access to education and intercultural education, for the two communities, building a positive experience and a safe "playground" for learning in an inclusive environment, through an integrated approach of the educational development.

\subsection{Health}

The third component of the program aimed to increase access to quality health care services in disadvantaged communities. In this context, Sastipen - The Roma Centre for Health Policies had attributes in developing an integrated system adapted to the needs of the communities. This system is conceived as an aggregate of socially viable and innovative tools that facilitate access to basic healthcare facilities for members of disadvantaged groups living in rural and small urban areas. Also, Terre des hommes had interventions whose objectives was to educate people in health-related issues. As such, the project focused on reducing inequalities in access to healthcare services by developing different types of activities:

1. Activities designed to improve health care infrastructure: Centres for medico-social assistance were established and equipped as to cover the needs of the local communities in which they were implemented. The centres were developed through an intensive consultation process with representatives of local authorities, formal and informal leaders, and relevant community members. Also, other medical institutions such as hospitals were equipped with medical appliances designed to aid in the diagnosis, monitoring or treatment of medical conditions. 
2. Activities designed to improve the quality of health care services: The staff working in the centres for medico-social assistance were trained as to assure the highest quality of first aid assistance and elementary medical services (primary consultations, campaigns for screening the risk factors or frequent affections, measurements of blood pressure and glycaemia etc.).

3. Activities designed to increase health literacy among community members: The project aimed to promote a healthy lifestyle by educating people to prevent and control various diseases which affect people in the community. Therefore, the campaigns informed people about diabetes, hypertension and cardiovascular diseases, hepatitis, tuberculosis, diabetes, cancer etc. Also, people belonging to disadvantaged groups participated in health promotion sessions that tackled themes like effects of tobacco and alcohol consumption. In addition, the campaigns included informative sessions about the importance of precocious diagnosing and medical counselling. Campaigns were organized not only in relation with the activity of the centres for medico-social assistance but also through detached initiatives conducted in a school setting. For example, "Education for Health" was a grant program that aimed to educate children to adopt a healthy lifestyle. In the context of the project, a special focus was placed on activities designed to improve maternal and infant health (monitoring the condition of new-born children, monitoring the pregnant women and lactating mothers, vaccination, and child care). Also, reproductive health was considered a relevant topic, thus being approached through informative sessions regarding contraception methods, pregnancy and parenting.

The health care centre was established in Ocolna, and its outcomes were notable through: a higher number of people included in prevention activities: pregnant women, children and old people, a better evidence of the health state of pregnant women, activities related to the situation of the community children, a better monitoring of the old people, awareness raising activities on health care education, formation activities; therefore through an integrated approach of many health aspects the project succeeded in increasing the access to health infrastructure, and the community members understanding of the need of such tools and information. All community members appreciated the importance and contribution of the health care centre. The relevance of this centre was very high and it properly responded to the need for such type of services.

\subsection{Housing}

The housing interventions aimed to facilitate social inclusion by securing better living conditions for families who live in poverty. Different aspects of housing are identified as potentially compounding factors associated with stigma and discrimination. The circumstances of households within local areas characterized by social and economic disadvantages are interrelated with low levels of education and 
employment among residents, thus being part of a complex mechanism that reinforce social exclusion and differentiated access to resources.

Therefore, housing interventions represent discrete techniques used to counterbalance some of the negative effects derived from practices of social or symbolic exclusion.

Therefore, housing is not considered as a separate component of the project but as a supporting intervention to education and health. It was designed to provide support to the most disadvantaged groups and to facilitate the development of trustful relations with beneficiaries.

On the above-mentioned rationales, Habitat for Humanity rehabilitated different buildings such as private houses, blocks of flats, or educational institutions (kindergartens). The buildings were improved according to specific needs and local particularities. However, the dwelling component was implemented only at Barca, where 80 houses were renovated. The renovation represented mounting of thermally insulated windows and works on house isolation.

\section{Conclusions}

\section{Integrated intervention in development projects}

The project clearly shows that communities cannot be supported with a single approach or isolated area, but needs an integrated approach that addresses the complexity of the issues at the community level. Community development activities have identified the following three key areas where integrated approach plays an important role in community development:

\section{a) The synergy between the top-down policies / programs and bottom-up planning}

Community development based only on a top-down approach leads to inefficient use of funds and produces poor results.

Activities were conceived and implemented by allowing beneficiaries to participate at all steps and components of the project, thus the interventions were constructed based on specific and documented needs. Community members were empowered to participate in the decision-making process at different levels throughout project implementation. In this sense, the project activities were expected to build trustworthy relationships among community members and ensure a local ownership of the project. The activities in the project were also anchored in an integrated approach. The project included multiple areas of interventions and proposed various solutions to the challenges faced by vulnerable groups, thus creating synergies among ongoing operations and activities. Taking in consideration social inclusion issues are complex and challenging, the project 
undertook a long-term perspective in which change was understood as a gradual process of cultural learning and capacity development.

\section{b) Coordination among different sectors and organizations}

An appropriate coordination mechanism linking the various plans and activities of community development organizations and institutions can catalyse different development needs of the community and contribute significantly to the global development community.

Such coordination cannot easily be achieved by creating a coordinating body at central or regional level. Furthermore, it is important to develop adequate knowledge between key stakeholders and attitudes regarding community development. In addition, the establishment of appropriate coordination structures and effective channels for information exchange, shared decision making, and collective action are needed.

Among the main strengths of the partnership there can be enumerated: Common values and vision regarding social issues; Complementarity in expertise; Social prestige and relevant past experiences; Previous collaboration with relevant national authorities.

\section{c) Co-operation between stakeholders}

In the case of an integrated approach as described above, many stakeholders are willing to engage in the development of the community, as well as people from the community, local leaders and organizations, local authorities and training institutes, NGOs etc. The challenge is to establish a cooperative attitude among all those involved in community development in order to develop actions and approaches that all move towards the same ideal.

The activities conducted in the field of education, health and housing were supported through community development interventions that relied on participatory approaches. Community development initiatives were focused on the identification and prioritization of socio-economic needs at local level, as to increase the general participation of community members in developing and implementing sustainable initiatives. Local problems were approached by mobilizing local resources to address identified community needs.

The main objective of the community development component was to empower local communities through leadership development and capacity building. Activities were directed towards mobilizing communities to exercise a greater control over their local contexts by fostering a sense of ownership of local policy decisions and programs. Another goal of the project was to improve the perception of Roma minority at local, regional and national levels, while cultivating self-confidence of community members in 
taking initiatives to improve their life conditions. Therefore, the project aimed to improve problem solving capabilities and enhanced intercommunity dialogue.

zefiR project's approach was based on involving all stakeholders. In some cases, the creation of LIGs was achieved with some impediments due to the relatively low educational level of community members willing to actively participate in community development.

However, the involvement of community members formed the basis of the horizontal integrated intervention and cooperation among all social actors.

Another substantial role was the participation of local authorities in different phases of the project. This action has made an important contribution to the efficiency of the implementation.

Attracting the representatives of the schools and of the medical institutions into the network completed the institutional framework and has made the integrated approach possible.

Therefore some of the benefits of integrated approaches identified include: the creation of a strong relation between partners and community members, realistic planning in community development activities, speeding up the initial process of needs analysis and creation of a flexible model for community intervention, local associations independent of local authority and cooperate effectively, capacity building of personnel in supporting vulnerable groups which is decisive to the success of the intervention, structures created for supporting the vulnerable groups (such as medical and social centres) are placed closely to the community, the flexibility and constant adaptation to the needs of vulnerable people (which have proved to lead to successful projects, the involvement of local authorities and usage of realistic and replicable models in accordance with funds available at local and county level, the authorities having an important role in enhancing citizen participation by conducting consultative processes and providing funds for community projects directly involving citizens.

\section{NOTES}

The research has been entirely funded by Fundația Agenția de Dezvoltare Comunitară Împreună. 


\section{Bibliography}

Jones, J., \& Wiggle, I. (1987). The Concept and Politics of "Integrated Community Development." Community Development Journal, 22(2), 107-119. https://doi.org/10.1093/cdj/22.2.107

Ryder, A. R., Rostas, I., \& Taba, M. (2014). 'Nothing about us without us': the role of inclusive community development in school desegregation for Roma communities. Race Ethnicity and Education, 17(4), 518-539. https://doi.org/10.1080/13613324.2014.885426

Sandu, D. (2005). Roma communities social map. https://doi.org/10.13140/RG.2.1.3408.5287

Masset, E. (2018). Integrated Development, Past and Present. IDS Bulletin, 49(4), 17-32.

Ruttan, V. W. (1984). Integrated rural development programmes: A historical perspective. World Development, 12(4), 393-401. https://doi.org/https://doi.org/10.1016/0305750X(84)90017-2 